\title{
Empirical Methods in Animal Ethics
}

\author{
Kirsten Persson ${ }^{1} \cdot$ David Shaw ${ }^{1}$
}

Accepted: 12 July 2015/Published online: 28 July 2015

(C) Springer Science+Business Media Dordrecht 2015

\begin{abstract}
In this article the predominant, purely theoretical perspectives on animal ethics are questioned and two important sources for empirical data in the context of animal ethics are discussed: (mostly qualitative) methods of the social and (mainly quantitative) methods of the natural sciences. Including these methods can lead to an empirical animal ethics approach that is far more adapted to the needs of humans and nonhuman animals and more appropriate in different circumstances than a purely theoretical concept solely premised on rational arguments. However, the potential tension between lay people's moral judgements and ethical theory must be handled with care. The thorough analysis of qualitative data can lead to a deep insight into e.g. ethical problems with the application of laws and guidelines, practicality issues with ethical theories, personal ambivalence, and cognitive biases. The interaction between animal ethics theory and empirical findings can lead to both a more context-sensitive and applicable ethical theory and a less arbitrary folk moral system. Findings from the natural sciences can also contribute valuable information to animal ethics theory - the more we know about the properties and preferences of nonhuman animals the better we can respect them. Here, however, it is vital not to justify invasive procedures for the sake of "ethical progress". It might be ethically required to forego some scientific findings about nonhuman animals if it is not clear how much a procedure would harm them. Only with robust empirical methods will light ultimately be shed on the nature of our moral relationship with animals.
\end{abstract}

Keywords Animal ethics · Qualitative research · Quantitative research · Human-animal relations · Empirical ethics

Kirsten Persson

Kirsten.Persson@unibas.ch

1 Institute for Biomedical Ethics, Universität Basel, Bernoullistrasse 28, 4056 Basel, Switzerland 


\section{Introduction}

In empirical medical ethics data are collected from different groups (patients, physicians, relatives, other stakeholders) to obtain an overview of and insight into ethically relevant medical processes. This can be done with the qualitative and quantitative methods of the social sciences (Sulmasy and Sugarman 2001). One necessary assumption: different perspectives - of those who treat and those who are treated-are important for analysis of ethical problems and finding solutions.

In animal ethics ${ }^{1}$ empirical data are hardly collected at all-it is mainly "armchair philosophy" (Schmidt 2011). However, animal ethicists make use of empirical facts for their arguments, regularly. Facts and figures on slaughtering and animal experiments (for example) frequently illustrate the urgency of various arguments when it comes to practical animal ethics (Gruen 2011; Lafollette 2011; Singer 2008; Gruzalski 2008; Rachels 2011). However, the collection of empirical data in a systematic way is more typical for psychologists dealing with the relationship between humans and nonhuman animals (Kavanagh et al. 2013; Signal and Taylor 2006; Loughnan et al. 2010) or animal welfare scientists (Mason and Latham 2004; Mintline et al. 2013a, b; Temple et al. 2011) than for philosophers.

There is literature on the relevance of empirical knowledge that might be crucial for animal ethics, though: On the one hand, it is claimed that findings about the abilities and properties of nonhuman animals are relevant (Schmidt 2011; Bortolotti 2007; Elwood et al. 2009; Broom 2007; Dawkins 2008). Properties of certain (groups of) nonhuman animals like the ability to experience pain or suffering, being self-conscious, or acting intentionally can be parts of ethical arguments. Therefore they need to be investigated as it can be questioned if (some) nonhuman animals meet the criteria for those ethical arguments. ${ }^{2}$ On the other hand from a biologistic evolutionist perspective (Würbel 2009; Wilson and Kellert 1993), or from a sociological/psychological point of view (Levine et al. 2005; Joy 2003), human behaviour/nature/attitudes are an important aspect of animal ethics: If a certain concept in ethics is in any way made for application, it is, for example, pivotal to know about people's moral reasoning. And these people cannot exclusively be philosophers who might have a special education for moral reasoning. In analogy to medical ethics, different groups should be considered-those who are treated (nonhuman animals) and those who treat (humans) — and empirical findings should be analysed together to obtain an overview and broad insight into both, nonhuman

\footnotetext{
1 In this paper "animal ethics" is understood in a rather narrow sense, referring to the philosophical field that developed in the 1970 s with Richard Ryder, Roslind and Stanley Godlovitch, Peter Singer and others who started thinking and writing about animal liberation and animal rights. Consequentialist and deontological approaches are considered to be the predominant ones while acknowledging that there is a broad spectrum of theories involving virtue ethics, care ethics, contractualism and many more (Wolf 2008).

2 This is e.g. illustrated in case of a project by the Swiss Federal Ethics Committee on Non-Human Biotechnology (ECNH): With publications from both fields, biology and philosophy, they present an interdisciplinary perspective on cognition, consciousness and pain in fish. Thereby, they provide the basis for a more profound ethical discussion about how this group of nonhuman animals should be treated.
} 
animals' minds and properties and folk morality. ${ }^{3}$ This cannot be done with the same set of methods for both groups, though, as social science methods are not applicable to nonhuman animals. Therefore, empirical animal ethics require an especially interdisciplinary approach, provided that the assumption that different perspectives are important to analyse ethical problems is accepted: The combination of qualitative/quantitative methods of the social sciences and behavioural research can a) reveal a deeper insight in human-animal-interaction on a descriptive level and b) question dominant circumstances and habits on a normative level.

\section{Why Empirical Data are Relevant for Animal Ethics}

\section{Empirical Ethics and the Use of Data}

Empirical data are related to ethics in several ways, depending on the approach and the meta-ethical level (e.g. applied ethics, empirical ethics, normative ethics, descriptive ethics, history of ethics) but also depending on the group of ethical subjects (medical ethics, environmental ethics, animal ethics etc.).

Advocates for "biologising" ethics tend to commit the is-ought-fallacy. ${ }^{4}$ In descriptive ethics it is not uncommon to try and find evolution-based explanations for moral behaviour (Wilson 2012; Kitcher 2011; Dawkins 1989), but it can be debated how much they have an impact on normative ethics. Krones (Krones 2009) suggests that we should stop drawing a clear line between "normative/prescriptive" and "empirical/descriptive" bioethics and between philosophers' and sociologists' work on bioethics. Thus, she argues that empirical and theoretical methods in ethics will lead to fruitful results if they interact: Moral theories should be considered falsifiable (through empirical findings), and also be context-sensitive and intertwined with practice in a way that ensures that the analysis of empirical data should always refer to a theoretical background. Bioethicists (here she is mainly referring to medical ethicists) should be competent in both, empirical methods and ethical theory so that they can not only examine data from natural and social sciences but are also able to collect and evaluate their data independently (Krones 2009).

For animal ethics, it is crucial to consider at least two key areas in addition to theoretical philosophical animal ethics: empirical research about nonhuman animals (their abilities, preferences, properties etc.) and about humans who deal with animals. As in a doctor-patient relationship, there are the ones who treat (pet keepers, farmers, veterinarians, zoo keepers, horse riders, fishers, laboratory

\footnotetext{
${ }^{3}$ Folk morality refers to the way people without a special philosophical education/qualification deal with moral problems. It has gained much attention recently by experimental philosophers or neuroethicists (Nichols and Knobe 2007; Kahane and Shackel 2008; Sytsma and Machery 2012) but it can additionally be investigated in a qualitative way, as suggested in this paper.

4 The expression „naturalistic fallacy”, also known as "is-ought-fallacy”, refers to several concepts of slightly different meanings (Engels 2008). Here it should be understood as: jumping from empirical, descriptive premises to a normative, evaluative conclusion without an explanation for the normative nature of the conclusion. A biologistic argument of that sort might be as follows: We found an evolutionary trend towards a certain trait, therefore we should prefer this trait/breed organisms with this trait/privilege those who carry this trait or consider this trait as something good.
} 
experimenters etc. and many people in everyday interactions with nonhuman animals) and those who are treated (nonhuman animals). For empirical ethics research it is pivotal to exhaustively investigate the perspectives and attitudes of both groups. The first part of this paper deals with the large group of moral agents and possible insights from empirical social sciences; the second part will be about empirical research results from natural sciences and their potential influence on animal ethics.

\section{Empirical Data from the Social Sciences}

In biomedical ethics the value of empirical research and data is substantially supported and argued for (Krones 2009; Herrera 2008; Hedgecoe 2004).

In principle, similar arguments that are put forward for the necessity of empirical research/data obtained with the methods of social sciences in biomedical ethics apply for animal ethics. The following points illustrating the purposes of empirical research with the methods of social sciences in medical ethics are taken from Rob de Vries and Bert Gordijn "Empirical ethics and its alleged meta-ethical fallacies" (de Vries and Gordijn 2009). It can be argued that all of them apply to animal ethics to some extent. According to the authors, empirical research is useful for the following purposes:

1. Description and analysis of the actual conduct of a group with respect to a morally relevant issue

a. describing compliance with existing moral norms

b. determining whether policies or procedures designed to operationalize certain moral norms have been successful (de Vries and Gordijn 2009)

2. Identification of moral issues that have escaped the attention of ethicists, but are relevant in a specific context (de Vries and Gordijn 2009)

3. Description and analysis of the actual moral opinions and reasoning patterns of those involved in a certain practice (de Vries and Gordijn 2009)

4. Making ethics more context-sensitive or realistic (de Vries and Gordijn 2009)

5. Description of facts relevant to normative arguments (de Vries and Gordijn 2009)

6. Showing the normative aspects of science, technologies or organizations (de Vries and Gordijn 2009)

In the context of empirical animal ethics, those aspects are-or should be-crucial in several ways:

1.

a. Compliance with existing moral norms is potentially interesting for people who are professionally involved in handling animals. As they have to obey certain laws and guidelines it could be worth investigating if they draw a distinction between what they should do according to the law and what they 
feel would be the morally right thing to do. On the other hand, this aspect can be investigated for all people who come in contact with nonhuman animals in their everyday life-which is basically everybody. When do people define an action involving nonhuman animals as "wrong" and which norms are important in those situations? Or do some people not see any difference at all between treating nonhuman animals according to a law/guideline and treating them in a morally correct way?

b. In contrast to the former aspect one can focus on the laws and guidelines that are (hopefully and probably) based on some ethics principle or approach; there are animal welfare laws on the European level and also in the individual countries and additional agreements like the Basel Declaration, the " $3 \mathrm{R}$ " or more specific rules at the institution level, which are constantly developed and modified. Interesting questions here include: Do people act differently when they are aware of a guideline? Do people, especially those who are not handling animals in a professional capacity, know about the different laws and do they see practical or moral obstacles in following them? Did the guidelines lead to any changes in the way nonhuman animals are handled?

2. In the field of farm animal welfare there is a broad current debate about the treatment and living conditions of farmed animals, the balancing of cost effectiveness versus improvement of the animals' well-being, the lack of control in the upbringing, transporting and slaughtering process etc. However, there are many animal ethics concepts which already suggest solutions to these problems, such as abandoning factory farming and engaging in so called "traditional farming" (DeGrazia 2011) or abolishing all kinds of animal use for nutrition purposes (Gruzalski 2008). Other fields which are less well covered by animal ethics are e.g. the treatment of wild animals or invertebrates. Empirical data-ecological data about wild animals and human-related problems as well as qualitative data about people's opinions - could enlighten these areas and point to potential ethical issues there. Both sides are important to define a problem, though: without knowledge of the facts (e.g. do wild boars suffer from our forest management?) the establishment of moral rules cannot be directed to any goal (e.g. wild boars should not be fed during wintertime); without the knowledge of people's awareness of the problem, there is no starting point for rules or guidelines.

3. Firstly, guidelines must be accepted by people to make sure they are put into practice. See point (1). And secondly, practices can be considered sources of morality: When something is a common practice in a cultural setting/society, it is less likely to be questioned and often enough considered "the moral norm". "Don't eat dogs" would be an example for a norm that is not established worldwide but just in certain cultural contexts and became a norm by practice. There is no consistent ethical theory explaining why we should eat pigs but not dogs, but there are cultural, practical and psychological explanations (Joy 2003). 
4. Context-sensitivity concerns finding out about potential success of a norm, which is especially important in the case of animal ethics: It leads away from questions like "can they suffer" or "does it matter whether their suffering can be compared to ours?" and more towards questions like "is it morally acceptable what we do in line with our norms/laws to those creatures which certainly do suffer". Also, morally irrelevant separations and distinctions, categories and arbitrary choices become obvious. Laws and guidelines take into account various aspects which are not related to moral considerations which is why some of them result in inconsistent moral claims: A "lab dog" and a "pet dog", for example, are protected by completely different laws, although they might have the same morally relevant properties. If someone wants to shoot a boar, she needs a hunting licence; in contrast to that, slaughterhouse workers just need a working contract with a slaughterhouse. They are often temporary workers who are not specifically educated for this kind of work (Sebastian 2014). In both cases the groups of animals treated do not differ in a morally relevant way. However, the laws are based on further aspects (freedom of science, protection of natural resources, public safety etc.) and lead to a different treatment.

Furthermore, if norms are too abstract, reduced to a few basic principles or based on calculus, it is unlikely that people are willing and able to stick to them in their context-dependent everyday life decisions. On the other hand, however, there is the danger of moral relativism if context-sensitivity is overrated. If, for example, the moral rule for dealing with nonhuman animals is only based on the individual relationship, it is different for every particular human-animalconstellation and a norm could hardly be identified. However, there are approaches to ethics which stress the importance of care and empathy (Donovan 1990, 2008). Aitken (Aitken 2004) even emphasises the role of relationships and individual care for nonhuman animals as a crucial factor for conservation ethics. Thus, the weight that is given to such non-rationalistic factors very much depends on the particular ethical position.

5. For animal ethics, the description of morally relevant facts refers to at least two questions: What are the empirical assumptions about humans dealing with animals and what are the assumptions about the properties of nonhuman animals?

The first would be answered e.g. by evolutionary biologists: How did the human-animal-relationship start and what motivated humans in the first place to care about animals? Or it could be discussed by psychologists: How do people cope with the ambivalences in their perspective on different kinds of nonhuman animals? Is it a matter of having a certain kind of personality if we agree to kill animals for certain purposes?

The second question would go to the expertise of biologists and animal welfare scientists and beyond. For example: What really matters to farm animals? Are the test tools we use to make predictions about their comfort, suffering, preferences etc. valid and reliable? Do our concepts of autonomy, well-being, pain, company etc. apply to nonhuman animals? Why did nonhuman animals choose to build relationships with humans? And additionally: the strong moral 
intuitions that build the basis of our ethical systems also need empirical support. What makes a creature important to us? Similarity, intelligence, the ability to feel pain, if we know it personally, if it is "cute"?

This second question will be discussed in the second part of this article in terms of the importance of the sciences for animal ethics.

6. The normative aspects of science and technologies are a very important factor e.g. in the current discussion about chimaera, GMO, inter-species organ transplantation or in vitro meat; but it also concerns the ethical aspects of all kinds of animal-related research in genetics, ecology, behavioural studies, neuroscience or medical experiments. It is common to find scientific publications dealing with one of these issues without raising ethical doubts at all (see e.g. Cooper et al. 2002). This lacking reflection points to one of many fields where animal ethics are neglected in empirical research, although nonhuman animals are undeniably affected.

\section{Empirical Data from the Natural Sciences}

As mentioned above, besides empirical data obtained with the methods of social sciences animal ethics can clearly benefit from findings in the natural sciences. In contrast to cases with human moral patients, we do not have access to preferences, opinions and satisfaction of nonhuman moral patients via verbally asking them. However, behavioural studies can give information about their cognitive and technical abilities, preferences, their social competences, emotions and their way of reasoning/problem solving (Koknaroglu and Akunal 2013). This type of interdisciplinary research has been argued for by philosophers as well as by natural scientists. For example Kirsten Schmidt points out three major arguments why findings in the sciences matter for normative animal ethics:

1. For moral subjects following pathocentric or sentientist ethics, it is indispensable to know more about nonhuman animals' ability to feel pain (Schmidt 2012), i.e. to suffer, or to be what Regan calls "subjects of a life" (Regan 1986). Recent findings about crustaceans, fish and cephalopods (Segner 2012; Conte 2004; Wild and Willemsen 2012; Elwood et al. 2009; Broom 2007) not only suggest that we as individuals should re-evaluate the way we treat those animals (e.g. when fishing or when boiling lobsters alive). In fact, even national or international laws, directives and guidelines explicitly add certain taxa like crustaceans and cephalopods to the group of vertebrates which is standard protected by animal welfare laws (Directive 2010/63/EU of the European parliament and of the council on the protection of animals used for scientific purposes, Official Journal of the European Union 2010; TSchV Schweiz, 2008; TierSchG Deutschland 2006). A change in scientific knowledge about certain properties of nonhuman animals thereby lead to a change in legally binding documents.

2. To be able to react to a creature's needs, we need research on this factor by using animal welfare science or animal psychology (Schmidt 2012). Tools have 
e.g. been developed to find out about (farm) animals preferences for certain kinds of housing (Dawkins and Beardsley 1986). Furthermore there have been attempts to assess the overall well-being of nonhuman animals on the basis of certain observable parameters (Temple et al. 2011; Weber and Zárate 2005; Mintline et al. 2013a, b; Sutton et al. 2013).

3. Schmidt also stresses the need for further scientific investigations of our moral reasoning about nonhuman animals as discussed in part 1 , but she emphasises the value of

a. psychological and

b. neurological findings (Schmidt 2012):

Gaining knowledge about the nature of our moral judgements and the way our brain categorises incidents and other beings could e.g. help convincing people to consider nonhuman animals as relevant moral patients in the first place. Research is especially needed and already ongoing — on both, the conceptual (Joy 2003) and practical (Loughnan et al. 2010) level-for certain cognitive biases. The aforementioned ambivalent relationship between humans and nonhuman animals of different kinds needs a thorough investigation if topics such as industrialised animal farming and vivisection should be addressed from a normative perspective. Additionally, these findings could be useful for educational purposes: For someone adopting a care ethics approach (Midgley 1983; Aaltola 2013; Donovan 2008), education on how to deal with nonhuman animals would be more effective e.g. if we knew more precisely how empathy evolved and can be encouraged in humans.

Further aspects about the relationship between natural sciences and animal ethics can be considered:

4. The problematic lack of communication between animal ethicists and animal welfare scientists has been exposed and the potential benefit of scientific exchange in this field has been discussed: Fraser (1999) is optimistic regarding the convergence of philosophy and sciences studying nonhuman animals and trying to answer the corresponding interdisciplinary questions. However, he criticises one largely neglected aspect: Several famous animal ethics theories do not sufficiently differentiate between

a. Different animal taxa: Talking about ethics for "nonhuman animals" emphasises the gap between humans and the rest of the animal kingdom although humans might have a lot more in common with e.g. great apes than these have with e.g. flatworms. "Treating animals" can therefore only be a very general issue that has to be differentiated when it comes to norms and guidelines.

b. Different ways of dealing with nonhuman animals: classifying e.g. all kinds of practices under the term "commercial animal agriculture" makes it 
impossible to address individual processes as commonly done in animal welfare sciences (Fraser 1999).

These two aspects are only examples for theoretical animal ethics missing a differentiation which is important for applied ethics.

5. It must additionally be considered that, depending on their properties, there might be the necessity to grant certain animals basic rights. This has been argued at least in the case of great apes and certain marine mammals (Grimm Grimm 2011; DeGrazia 1997). Two well-known and recent approaches are the great ape project and the Zoopolis concept: The former, founded by Peter Singer and Paola Cavalieri, claims three basic rights explicitly for the group of great apes in its "World declaration on great primates", 5 which it ultimately wants to be accepted by the United Nations: the right to life, the protection of individual freedom and the prohibition of torture. The argumentation is based to a large extent on the physical and mental similarity between humans and great primates.

The latter approach suggests different legal rights to certain groups of animals according to their relationship with human society: Donaldson and Kymlicka (Donaldson and Kymlicka 2011) suggest that domestic animals should be given citizenship as they are members of our society. Wild animals are considered to have their own societies and their sovereignty as such should be protected. A third group-animals living among humans like racoons, insects or ratsshould be considered "denizens", i.e. getting some but not all rights of full citizens. Thus, in this case, crucial criteria are not species-specific or individual properties but the relation to human society which initially has to be investigated for every group of nonhuman animals.

\section{Discussion}

The question about the relationship between "folk moral" findings and normative claims is, of course, not restricted to animal ethics. The intersection between philosophical and psychological objects of research is e.g. also investigated by experimental philosophers: they are interested in psychological processes underlying philosophical phenomena (like moral decisions), so they conduct and analyse thought experiments systematically (Knobe and Nichols 2007). Their findings about people's (and not barely philosophers') intuitions regarding philosophical concepts are remarkable; the Knobe Effect $^{6}$ (Knobe 2003) is just one example. Consequently,

\footnotetext{
5 http://www.projetogap.org.br/en/world-declaration-on-great-primates/.

6 The "Knobe effect" is the name for the main result of a study by Joshua Knobe in 2003: in his thought experiment he presented the situation of a chairman who decides to start a profitable program knowing that its side effects will in case a) harm and in case (b) help the environment. The man does not care about the environment at all but is just interested in the company's profit. When the program starts and the environment is in (a) harmed and in (b) helped, the experiment's participant is asked if the chairman
} 
they argue that "empirical evidence can (and should) play a positive role in ethical theorising" (Kahane 2013). A thorough discussion of experimental philosophers' methods and their meaning for ethical theory would, however, go beyond the scope of this paper.

Whereas they ground their research on quantitative data-by analysing their thought experiments statistically - the importance of qualitative data should not be neglected. On the one hand ideas for quantitative analysis can inductively be found in qualitative data. Interviews can present a source of individual opinions whose intersubjectivity might be worth testing, especially if they contradict the theoretical ethicist's rational argumentation-e.g. about individual experiences with nonhuman animals, about the ambivalences in the human-animal-relationship, about nonhuman animals' dignity, value or status. On the other hand, qualitative data provide a range of perspectives, arguments and more complex reasoning that cannot be detected by standardised questioning.

However, for both, quantitative and qualitative data, normative claims can only be proposed carefully to avoid the is-ought-fallacy. If a majority of the participants in an empirical study intuitively judges an action as morally correct there might still be good reasons to call it ethically wrong. Moral intuitions can be common and still incoherent, contradictive or unjustified. At the same time, findings from the natural sciences can lead to reductionist conclusions: If we find out that a group of nonhuman animals is e.g. more intelligent than we thought, it does not immediately tell us more about how we should treat them. Ethicists must especially beware of anthropomorphisation: A prima facie human-like feature like e.g. the ability to use a sign language could easily be seen as a morally relevant property of Species X. However, Species Y might not be able to use sign language for anatomic reasons but still have the same morally relevant properties as Species $X$ and should therefore be morally considered in the same way. Let's say you find yourself in a dilemma situation: You stand in front of three cages which are about to be burned by a huge fire. You can only rescue one of the three creatures sitting in the cages. The first is a non-sentient robot-like creature which eloquently tries to convince you to save it. The second is a human-like creature not showing any signs of sentience or communication skills. The third is a snail-like creature screaming in pain. Which would you rescue? ${ }^{7}$ Explaining why opinions, properties and preferences are morally relevant cannot be skipped and the mere reference to our own species cannot be considered sufficient.

However, it must be taken into consideration, that ethics only make sense if they are applicable. If the conclusions of a moral theory are counter-intuitive, and are not at all in line with "folk moral" judgements, they are only valuable for the armchair philosopher's theory collection. This is especially true for animal ethics as people's personal moral judgements are frequently demanded in this field: there are only very

Footnote 6 continued

(a) harmed and (b) helped the environment intentionally and if he was to be blamed/praised. Although the modification between (a) and (b) is not immediately related to the concept of intentionality, more than $80 \%$ of the participants thought that the chairman harmed the environment intentionally whereas over $70 \%$ found that he did not help the environment intentionally.

7 This example is part of the authors' empirical work with thought experiments. 
few clear legal regulations for every-day interactions with nonhuman animals, but so many choices affecting nonhuman animals morally-more obvious ones like dealing with pets or enjoying activities like horseback riding and visiting zoos/circuses or more subtle ones like the consumption of animal products, the use of resources in competition with free living animals etc. Institutionalised use of nonhuman animals such as factory farming, captivity in zoo cages and torture breeding are directly supported through consumer behaviour. Thus, people have to make numerous (consumption) decisions in their everyday life which affect nonhuman animals without having obvious guiding principles to hand. The lack of awareness of the crucial connection between choices in everyday life and consequences for nonhuman animals, as e.g. claimed in the concept of carnism (Joy 2003), might even be enforced by the fact that there are no restricting laws. While there are laws concerning factory farming, breeding, hunting or keeping nonhuman animals in zoos, they affect mostly professionals and even these people might have a moral perspective on their actions that differs from their legal duty. Lay people, however, if they think about the consequences of their actions at all, must rely on their own set of moral rules when it comes to questions like: Is it acceptable to use cosmetics that were tested on nonhuman animals? Are we allowed to eat foie gras? Is it sustainable to consume this steak? Do I want my child to watch a great ape behind plexiglass windows? If an animal ethics theory is meant to provide more than an animal welfare law, people's intuitions, situation-specific circumstances and properties/preferences of the nonhuman animals must therefore be taken into account. Raising awareness about the effects of every-day choices can be an additional goal of empirical animal ethics.

An important aspect of empirical data from the natural sciences is the following paradox: some potentially morally relevant properties of nonhuman animals (e.g. being able to feel pain or stress) could be investigated in a way that would not have been legally allowed if the outcome (e.g.: that a creature is able to feel pain or stress) had been known beforehand. Animal experiments that are painful or stressful, but also tests aiming at showing that certain species behave altruistic or compassionately are occasionally cruel for creatures with these precise properties. It should therefore be discussed (elsewhere) if the scientific method is always appropriate to scrutinise the possession of certain properties which are part of an anthropomorphic ethical framework. It is rather to be questioned to what extend knowledge about these properties is necessary and what means are adequate to gain that knowledge.

Another difficulty is the challenge that interdisciplinary methods present to an animal ethics researcher: If she understands herself as an empirical ethicist and wants to collect all data herself she must be competent in the methods of natural and social sciences and in ethical theory-or have access to an interdisciplinary team that is familiar with the research questions. This is especially the case with regard to the aforementioned argument: if research is aiming at meaningful results for ethical theory and at the same time does not want to harm nonhuman animals it will in most cases be necessary to design and conduct the studies by oneself. Simply using the results of animal welfare studies would e.g. implicitly acknowledge their methods and hypotheses, although they might be ethically questionable, as mentioned earlier: 
Finding out about animals' properties and preferences might already include doing harm. A thorough education in all related disciplines is therefore required for those working in the field of empirical animal ethics. However, the dialogue between researchers in different scientific fields (social sciences, psychology, animal welfare studies, behavioural biology etc.) could already provide a first insight into questions that can be investigated with interdisciplinary empirical animal ethics.

\section{Key Findings}

The combination of a range of empirical methods can lead to an empirical animal ethics approach that is far more adapted to the needs of humans and nonhuman animals and more appropriate in different circumstances and situations than a purely theoretical concept solely premised on rational arguments.

However, the potential tension between lay people's moral judgements and ethical theory must be handled with care. The thorough analysis of qualitative data can lead to a deep insight into e.g. ethical problems with the application of laws and guidelines, practicality issues with animal ethics theories, personal ambivalence, and cognitive biases. All these phenomena call for interpretation or possible explanations. The interaction between animal ethics theory and empirical findings with the methods of social sciences can lead to both a more context-sensitive and applicable ethical theory and a less arbitrary folk moral system.

Findings from the natural sciences can also contribute valuable information to animal ethics theory-the more we know about the properties and preferences of nonhuman animals the better we can consider and respect them. Here, however, it is vital not to justify invasive procedures for the sake of "ethical progress". It might be ethically required to forego some scientific findings about nonhuman animals if it is not clear how much a procedure would harm them. Behavioural studies with free living animals should be considered as an alternative if possible.

Funding Kirsten Persson's research is supported in part by the Haldimann Stiftung in Aarau, Switzerland. All other support for all authors came from the University of Basel.

\section{Compliance with Ethical Standards}

Conflicts of interest There is no conflict of interest.

\section{References}

Aaltola, E. (2013). Skepticism, empathy, and animal suffering. Journal of Bioethical Inquiry, 10(4), 457-467.

Aitken, G. (2004). A new approach to conservation: The importance of the individual through wildlife rehabilitation. London: Ashgate.

Bortolotti, L. (2007). Disputes over moral status: Philosophy and science in the future of bioethics. Health Care Analysis, 15(2), 153-158.

Broom, D. (2007). Cognitive ability and sentience: Which aquatic animals should be protected? Diseases of Aquatic Organisms, 75(2), 99-108. 
Conte, F. S. (2004). Stress and the welfare of cultured fish. Applied Animal Behaviour Science, 86(3-4), 205-223.

Cooper, D. K. C., Gollackner, B., \& Sachs, D. H. (2002). Will the pig solve the transplantation backlog? Annual Review of Medicine, 53(1), 133-147.

Dawkins, R. (1989). The selfish gene. 1976, revised edn. Oxford: Oxford University Press.

Dawkins, M. S. (2008). The science of animal suffering. Ethology, 114(10), 937-945.

Dawkins, M. S., \& Beardsley, T. (1986). Reinforcing properties of access to litter in hens. Applied Animal Behaviour Science, 15(4), 351-364.

de Vries, R., \& Gordijn, B. (2009). Empirical ethics and its alleged meta-ethical fallacies. Bioethics, 23(4), 193-201.

DeGrazia, D. (1997). Great apes, dolphins, and the concept of personhood. The Southern Journal of Philosophy, 35, 301-320.

DeGrazia, D. (2011). The ethics of confining animals: From farms to zoos to human homes. In R. Frey \& T. Beauchamp (Eds.), The Oxford handbook of animal ethics (pp. 738-768). New York: Oxford University Press.

Donaldson, S., \& Kymlicka, W. (2011). Zoopolis: A political theory of animal rights. Oxford: Oxford University Press.

Donovan, J. (1990). Animal rights and feminist theory. Signs, 15(2), 350-375.

Donovan, J. (2008). Aufmerksamkeit für das Leiden. Migefühl als Grundlage der moralischen Behandlung von Tieren. In Wolf, U. (ed), Texte zur Tierethik. Stuttgart, Philipp Reclam jun. $\mathrm{GmbH} \& \mathrm{Co}$.

Elwood, R. W., Barr, S., \& Patterson, L. (2009). Pain and stress in crustaceans? Applied Animal Behaviour Science, 118(3-4), 128-136.

Engels, E.-M. (2008). Was und wo ist ein "naturalistischer Fehlschluss"? In C. E. Brand, E.-M. Engels, A. Ferrari, \& L. Kovacs (Eds.), Wie funktioniert Bioethik. Mentis: Paderborn.

Fraser, D. (1999). Animal ethics and animal welfare science: Bridging the two cultures. Applied Animal Behaviour Science, 65(3), 171-189.

Grimm, (2011). Are dolphins too smart for captivity? Science Magazine, 332, 526-529.

Gruen, L. (2011). Ethics and animals: An introduction. Cambridge: Cambridge University Press.

Gruzalski, B. (2008). Warum es falsch ist, Tiere zu essen, die zur Nahrungsgewinnung gezüchtet und geschlachtet wurden. In U. Wolf (Ed.), Texte zur Tierethik. Leipzig: Reclam.

Hedgecoe, A. M. (2004). Critical bioethics: Beyond the social science critique of applied ethics. Bioethics, 18(2), 120-143.

Herrera, C. (2008). Is it time for bioethics to go empirical? Bioethics, 22(3), 137-146.

Joy, M. (2003). Psychic numbing and meat consumption: The psychology of carnism. Dissertation, Saybrook Graduate School and Research Centre, San Fransisco.

Kahane, G. (2013). The armchair and the trolley: an argument for experimental ethics. Philosophical Studies, 162(2), 421-445.

Kahane, G., \& Shackel, N. (2008). Do abnormal responses show utilitarian bias? Nature, 452(7185), E5.

Kavanagh, P. S., Signal, T. D., \& Taylor, N. (2013). The Dark Triad and animal cruelty: Dark personalities, dark attitudes, and dark behaviors. Personality and Individual Differences, 55(6), $666-670$.

Kitcher, P. (2011). The ethical project. Cambridge: Harvard University Press.

Knobe, J. (2003). Intentional action and side effects in ordinary language. Analysis, 63(279), $190-194$.

Knobe, J., \& Nichols, S. (2007). An experimental philosophy manifesto. In J. Knobe \& S. Nichols (Eds.), Experimental philosophy. Oxford: Oxford University Press.

Koknaroglu, H., \& Akunal, T. (2013). Animal welfare: An animal science approach. Meat Science, 95(4), $821-827$.

Krones, T. (2009). Empirische Methodologien und Methoden der angewandten und der empirischen Ethik. Ethik in der Medizin, 21(3), 247.

Lafollette, H. (2011). Animal experimentation in biomedical research. In T. L. B. R. G. Frey (Ed.), The Oxford handbook of animal ethics (pp. 796-825). New York: Oxford University Press.

Levine, E. D., Mills, D. S., \& Houpt, K. A. (2005). Attitudes of veterinary students at one US college toward factors relating to farm animal welfare. Journal of Veterinary Medical Education, 32(4), 481.

Loughnan, S., Haslam, N., \& Bastian, B. (2010). The role of meat consumption in the denial of moral status and mind to meat animals. Appetite, 55(1), 156-159. 
Mason, G., \& Latham, N. (2004). Can't stop, won't stop: is stereotypy a reliable animal welfare indicator? Animal Welfare-Potters Bar Then Wheathampstead, 13, S57-S70.

Midgley, M. (1983). Animals and why they matter. Georgia: University of Georgia Press.

Mintline, E. M., Stewart, M., Rogers, A. R., Cox, N. R., Verkerk, G. A., Stookey, J. M., et al. (2013a). Play behavior as an indicator of animal welfare: Disbudding in dairy calves. Applied Animal Behaviour Science, 144(1), 22-30.

Mintline, E. M., Stewart, M., Rogers, A. R., Cox, N. R., Verkerk, G. A., Stookey, J. M., et al. (2013b). Play behavior as an indicator of animal welfare: Disbudding in dairy calves. Applied Animal Behaviour Science, 144(1-2), 22-30.

Nichols, S., \& Knobe, J. (2007). Moral responsibility and determinism: The cognitive science of folk intuitions. Nous, 41(4), 663-685.

Rachels, S. (2011). Vegetarianism. In T. Beauchamp \& R. Frey (Eds.), The Oxford handbook of animal ethics. New York: Oxford University Press.

Regan, T. (1986). A case for animal rights. In M. W. F. L. D. Mickley (Ed.), Advances in animal welfare science (pp. 179-189). Washington, DC: The Humane Society of the United States.

Schmidt, K. (2011). Concepts of animal welfare in relation to positions in animal ethics. Acta Biotheoretica, 59(2), 153-171.

Schmidt, K. (2012). Naturalizing Ethics. EurSafe, 14(2), 2-6.

Sebastian, M. (2014). In den Schlachthöfen der Welt. In H.-B. S. B. L. M. Diplomatique (Ed.), Fleischatlas 2014 (pp. 18-19). Daten und Fakten über Lebensmittel: Eigenverlag.

Segner, H. (2012). Fish: Nociception and Pain: a Biological Perspective. Federal Office for Buildings and Logistics (FOBL).

Signal, T. D., \& Taylor, N. (2006). Attitudes to animals: Demographics within a community sample. Society \& Animals, 14(2), 147-157.

Singer, P. (2008). Tierversuche. In U. Wolf (Ed.), Texte zur Tierethik. Leipzig: Reclam.

Sulmasy, D. P., \& Sugarman, J. (2001). The many methods of medical ethics (or, thirteen ways of looking at a blackbird.). Methods in Medical Ethics 3-18.

Sutton, G. A., Dahan, R., Turner, D., \& Paltiel, O. (2013). A behaviour-based pain scale for horses with acute colic: Scale construction. Vet J, 196(3), 394-401.

Sytsma, J., \& Machery, E. (2012). The two sources of moral standing. Review of Philosophy and Psychology, 3(3), 303-324.

Temple, D., Manteca, X., Velarde, A., \& Dalmau, A. (2011). Assessment of animal welfare through behavioural parameters in Iberian pigs in intensive and extensive conditions. Applied Animal Behaviour Science, 131(1), 29-39.

Weber, R. E., \& Zárate, A. V. (2005). Der Begriff Wohlbefinden in der Nutztierhaltung-Diskussion aktueller Definitionsansätze als Grundlage für praxisorientierte Forschung am Beispiel Mastschweinehaltung. Archiv Tierzucht, Dummerstorf, 48(5), 475-489.

Wild, M., \& Willemsen, A. (2012). Fische: Kognition. Bundesamt für Bauten und Logistik BBL: Bewusstsein und Schmerz; eine philosophische Perspektive.

Wilson, E. O. (2012). On human nature. Cambridge: Harvard University Press.

Wilson, E. O., \& Kellert, S. R. (1993). The biophilia hypothesis. Washington, DC: Island.

Wolf, U. (2008). Texte zur Tierethik. Leipzig: Reclam.

Würbel, H. (2009). Ethology applied to animal ethics. Applied animal behaviour science, 118(3-4), 118-127. 